Produto \& Produção, vol. 13 n. 1, p. 34-58, fev. 2012

\title{
Configurador de produto para a customização em massa na indústria automobilística
}

Recebido em 01/11/2011.Aceito em 03/02/2012.

\section{Diego Castro Fettermann}

Programa de Pós-Graduação em Engenharia de Produção - PPGEP/UFRGS

dcfettermann@gmail.com

\section{Márcia Elisa Echeveste}

Departamento de Estatística /UFRGS

echeveste@producao.ufrgs.br

\section{Vera Lúcia Milani Martins \\ Programa de Pós-Graduação em Engenharia de Produção - PPGEP/UFRGS vlmmartins@producao.ufrgs.br}

A estratégia de Customização em Massa (CM) depende da disponibilidade de requisitos internos de manufatura e desenvolvimento de produto, algumas condições de mercado além da forma como a empresa atua neste mercado, representada neste estudo pelas variáveis comerciais. O objetivo deste trabalho é analisar a associação entre variáveis comerciais das empresas com o uso do configurador online de produto utilizado como suporte à estratégia de $\mathrm{CM}$ e em um segundo momento, a associação destas variáveis com os recursos que integram estes configuradores. Para tanto, realizou-se uma survey com fontes de dados secundária. Os resultadosforamobtidos por meio da análise de correlação estatística biserialedestacam as variáveis quantidade de carros vendidos, dimensão do mercado e variedade de modelos como significativamente correlacionadas com a utilização do configurador online de produto além da combinação de recursos dos configuradores mais associada a venda de veículos.

Palavras chave: Customização em massa; Configuradores de produto; Correlação biserial (rpb).

The strategy of Mass Customization (MC) depends on the availability of internal requirements of manufacturing and product development, some market conditions and how the company interacts with the market, depicted in this paper by the business variables. The objectiveofthis paper is to verify an association between online configurators used to support MC strategy and their features with business variables of automobile companies. The survey carried out with secondary data sources was analyzed by biserial correlation (rpb). It identifies the correlations between the online configuration and the following business variables: cars sold, 
market size and product range. This survey also identifies which online configurator set of features correlate with an increase in thesaleofvehicles.

Keywords: Mass Customization; Product configurator;Biserial correlation (rpb).

\section{INTRODUÇÃO}

O crescimento da expectativa dos consumidores em relação aos produtos tem exigido das empresas um tratamento diferenciado aos clientes, com isto a utilização da técnica de segmentação de mercado para atender a características específicas de mercados alvo tende a ser superada por um tratamento diferenciado e individualizado para cada cliente (SIMONSON, 2005). Simultaneamente, o desenvolvimento de novas tecnologias de manufatura tem contribuído para reduzir os efeitos prejudiciais de uma maior variedade de produtos na produção, mantendo as vantagens de economia de escala mais próximas das obtidas pela produção em massa (HART, 1994; KOTHA, 1995; DA SILVEIRA et al, 2001; FRANKE; PILLER, 2003; PILLER, 2007).

Uma abordagem sugerida para atender esta maior diversidade do mercado é a Customização em Massa (CM), que tem por característica empregar as novas tecnologias de manufatura para direcionar o processo produtivo ao atendimento da necessidade individual do cliente (DAVIS, 1987; GILMORE; PINE, 1997; PINE, 1993). A adoção da CM está relacionada à habilidade em disponibilizar produtos ou serviços customizados por meio de processos produtivos flexíveis com grande volume de produção e a um custo baixo (DA SILVEIRA et al, 2001), sendo que sua operacionalização somente é possível com o desenvolvimento de processos de manufatura flexíveis e mecanismos para integrar o cliente ao processo de desenvolvimento de produto (PILLER, 2004).

$\mathrm{Na} \mathrm{CM}$, a venda de cada produto implica no contato direto entre cliente e empresa, resultando em troca de informações e coordenação do projeto customizado para o cliente (PINE II, 1993; DURAY et al, 2000; PILLER et al, 2004). A participação do cliente durante o processo de desenvolvimento do produto passa a ser indispensável para a adoção da CM (DURAY et al, 2000). Mecanismos para facilitar esta comunicação entre cliente e empresa durante o projeto e especificação do produto são considerados um dos principais determinantes para o sucesso da adoção da estratégia de CM (OGAWA; PILLER, 2006), além de um dos principais desafios para a sua adoção (PINE, 1993; TSENG; DU, 1998).

Esta comunicação entre cliente e empresa utiliza mecanismos a fim de captar e processar as necessidades e desejos específicos de cada cliente e traduzi-las em especificações de um produto ou serviço customizado. O estudo sobre como deve acontecer essa interação tem sido estudo de diversos trabalhos recentes (SIMONSON, 2005; DELLAERT; STREMERSCH, 2005; FANG, 2008; RANDALL et al, 2007; FOGLIATTO; DA SILVEIRA, 2008; FRANKE et al, 2008; FRANKE et al, 2009; FRANKE et al, 2010). A maior parte desta interação com o cliente acontece durante a configuração do produto (FRANKE; PILLER, 2003). Uma alternativa para estabelecer esta interação com o cliente durante a configuração do produto é utilizando um mecanismo denominado de configurador de produto. Seu principal objetivo é guiar o cliente durante o processo de configuração (PILLER, 2004), permitindo ao consumidor projetar o seu próprio produto combinando as 
características de acordo com as suas necessidades (LIETCHY et al, 2001). O configurador de produto consiste em uma ampla rede de interfaces entre cliente e empresa para a configuração do produto customizado. Esta rede de interfaces pode ser desde um encadeamento de opções pré-determinadas para a configuração do produto final até sistemas mais complexos que permitem a intervenção no processo de projeto, comparação e atualização dos custos para a customização (URBAN; HAUSER, 2004). A utilização da internet tem se constituído uma eficiente alternativa para estabelecer esta rede de interfaces entre cliente e empresa (PILLER, 2007; FRUTOS; BORENSTEIN, 2004; LIETCHY et al, 2001; FRANKE; PILLER, 2003; PILLER, 2004).

A utilização do configurador de produto como uma ferramenta de suporte a estratégia de CM consiste em uma alternativa para permitir ao cliente configurar o seu produto de acordo com as suas necessidades. A disponibilização do configurador é mencionada na literatura como uma importante ferramenta comercial para as empresas (LIETCHY et al, 2001; FRANKE; PILLER, 2003; PILLER, 2004; FOGLIATTO; DA SILVEIRA, 2008; FRANKE et al, 2009; FRANKE et al, 2010). Sob este tema, foram desenvolvidos diversos estudos que procuram comprovar o valor agregado ao produto a partir da aplicação estratégia de CM com a disponibilização do configurador online de produto (FRANKE; PILLER, 2004; CHANG; CHEN, 2009; FRANKE et al, 2009; FRANKE et al, 2010).

No caso do estudo de Franke e Piller (2004), é realizado um experimento simulado para a compra de relógios com 164 alunos de graduação em administração, os resultados apresentam uma maior diposição de pagar a mais pelos relógios montados no configurador online que os escolhidos 'ontheshelf'. Outro estudo encontra resultados semelhantes analisando a disposição em pagar a mais por um jornal em que as informações (notícias) fossem customizadas de acordo com o perfil do cliente (FRANKE et al, 2009). Chang e Chen (2009) desenvolvem um experimento com 380 alunos de ensino médio e graduação simulando a compra de diferentes produtos pela internet. Entre os produtos com compra simulada, uma primeira parte realizou a compra de produtos padronizados e outra simulou a compra de produtos customizáveis. Foi verificada uma intenção de compra por parte dos usuários significativamente superior após a utilização do configurador de produto, além de uma maior satisfação dos mesmos. Este resultado também foi verificado por Frankeetal (2010) com uma amostra de 114 alunos de graduação simulando a compra de três diferentes produtos por meio da utilização do configurador onlinede produto. Como forma de identificar as vantagens comerciais pela possibilidade de configuração online do produto, estes trabalhos tem como principais características: aplicar experimentos simulados, utilizar variáveis baseadas em escalas intervalares mensurando o nível de satisfação do usuário, contudo esses estudos foram aplicados em amostras não representativas e concentradas em alunos de graduação (FRANKE; PILLER, 2004; CHANG; CHEN, 2009; FRANKE et al, 2009; FRANKE et al, 2010).

Estes estudos mencionam vantagens na adoção da estratégia de CMvinculada ao configurador de produto . Esta recomendação é direcionada principalmente para mercados maduros, com produtos de curtos ciclo de vida e com demanda heterogênea (PAN; HOLLAND, 2006). Entretanto, mesmo em mercados com estas características, verifica-se que a adoção desta estratégia frequentemente tem por consequência uma redução do desempenho operacional da empresa, muito em razão de que a maior quantidade de diferenciação nos produtos resultar em maiores custos de manufatura, custos indiretos, altos níveis de estoques e maiores 
tempos de produção (SALVADOR et al, 2002). Além disto, os custos relacionados ao desenvolvimento e manutenção do configurador também podem se apresentar como variáveis importantes para se decidir por esta estratégia. Desta forma, a viabilidade da adoção da estratégia de $\mathrm{CM}$ com a disponibilização do configurador de produto além de atender aos requisitos internos da empresa, principalmente relacionados ao sistema produtivo e a integração do cliente (PINE, 1993) e do mercado, também pode estar associada a características comerciais da empresa. Estas características comerciais estão relacionadas na forma como a empresa atua neste mercado e estão localizadas na interface entre a empresa e o mercado. Nesta interface, algumas questões ainda precisam ser melhor compreendidas, tais como: (i) a quantidade de vendas da empresa no mercado está associada ao uso doconfiguradoronlinedo produto utilizado na estratégia de CM? (ii) a dimensão do mercado disponível está associada à utilização do configurador online do produto utilizado na estratégia de CM? (iii) o tamanho do portfólio de produtos oferecidos pela empresa está associado à disponibilização do configurador online do produto utilizado na estratégia de CM?

Como forma de responder a estas questões, o presente trabalho tem por objetivo analisar a associação entre as variáveis comerciais das empresas com a utilização do configurador online do produto utilizado na estratégia de CM e em um segundo momento, a associação destas variáveis com os recursos que integram estes configuradores.Comopopulação alvo foram selecionadas empresas do setor automobilístico. Consiste em um setor tradicional da economia, com uma alta taxa de substituição de produtos, demanda diversificada além da disponibilidade de tecnologias de manufatura, características estas que recomendam a estratégia de CM (PAN; HOLLAND, 2006, BARDAKCI; WHITELOCK, 2004), inclusive com a utilização do configurador online de produto.

Foram selecionadas três variáveis comerciais das empresas para descrever a interface entre a empresa e o mercado que podem ser relevantes para a viabilidade da utilizaçãodo configurador online do produto.Para mensurar o volume de vendas da empresa foi selecionada a variável quantidade de carros vendidos pela empresa no mercado de atuação do configurador de produto. Como forma de mensurar a dimensão do mercado atendido pelo configurador de produto foi utilizada a variável quantidade de registros de novos veículos no mesmo mercado de atuação do configurador. Para mensurar a variedade do portfólio de produtos foi selecionada a variedade de modelos de carros oferecidos pela empresa no mercado de atuação do configurador de produto. A escolha pelo estudo no setor automobilístico, assim como das variáveis comerciais selecionadas acontece também pela sua disponibilidade de fontes de dados secundárias. Neste estudo foram utilizadas como fonte de dados relatórios anuais das empresas (anual reports), relatórios das associações nacionais de fabricantes de veículos e as próprias páginas de internet das empresas.

Este artigo está estruturado em cinco seções. A primeira seção consiste em uma introdução sobre o tema e a problemática abordada. A segunda seção apresenta a revisão de literatura sobre os temas de CM, envolvimento do cliente na $\mathrm{CM}$, configuradores de produto e finaliza com a apresentação das hipóteses de pesquisa. A terceira seção apresenta o método de pesquisa empregado, 0 procedimento de coleta da amostra utilizada assim como os dados e variáveis analisadas. Os resultados obtidos para as hipóteses de pesquisa são apresentados e discutidos na quarta seção. A última seção apresenta as conclusões e recomendações para trabalhos futuros. 


\section{REVISÃO DE LITERATURA}

A teoria abordada neste estudo está concentrada no tema da estratégia de Customização em Massa. O desdobramento deste tema aborda a necessidade de envolvimento do cliente durante o processo de customização e alternativa de utilização do configurador online de produto como alternativa para estabelecer esta interação entre cliente e empresa. Ao final desta revisão são apresentadas as hipóteses de pesquisa que orientam a realização deste trabalho.

\subsection{Customização em Massa}

O termo Customização em Massa (CM) foi elaborado durante a década de 1980 como a estratégia capaz de atender a grande quantidade de clientes dos mercados de massa, desenvolvidos durante a era industrial, e ao mesmo tempo tratá-los individualmente, como na produção artesanal (DAVIS, 1987). Os principais princípios que sustentam as vantagens propostas pela CM são: a utilização de manufatura flexível (FMS) (KOTHA, 1995; DA SILVEIRA et al, 2001, FRANKE; PILLER, 2003; PILLER, 2004), as técnicas e práticas aplicadas durante o processo de desenvolvimento de produto, principalmente a modularidade (SALVADOR et al, 2002, GILMORE; PINE II, 1997; JOSE; TOLLENARE, 2005) e pelos mecanismos de integração do cliente ao processo de customização (PILLER, 2004; FRANKE et al, 2010).

Como forma de suportar a customização dos produtos, o desenvolvimento de uma plataforma de produto deve atender aos requisitos definidos e ao mesmo tempo permitir a rápida configuração e alteração de módulos e componentes de modo a atender as necessidades específicas de cada cliente. Para atingir este objetivo são utilizadas diversas técnicas, sendo a modularização dos produtos a mais comumente empregada (SALVADOR et al, 2002; GILMORE; PINE II, 1997; JOSE; TOLLENARE, 2005). A modularidade nos produtos possibilita a combinação de características e módulos do produto por meio de um configurador de produto. Este processo de combinação de características e módulos utilizando o configurador de produto tem como resultado um produto customizado de acordo com as necessidades individuais dos clientes. Para isto, o desenvolvimento de produto deve disponibilizar uma quantidade restrita de módulos, que a partir de sua combinação, possam atender uma maior quantidade de necessidades individuais dos clientes ao mesmo tempo em que são mantidos os ganhos de escala de desenvolvimento e produção. Desta forma, a CM exige uma eficiente coordenação do portfólio de plataformas/módulos/componentes (BARE; COX, 2008), a fim de manter reduzidos os custos de manufatura, custos indiretos, níveis de estoques e tempos de produção resultantes de um maior portfólio de produtos (SALVADOR et al, 2002). 


\subsection{Envolvimento do cliente na CM}

Integrar clientes durante o processo de projeto e produção consiste em uma estratégia promissora nos mercados em que é crescente a individualização da demanda (FRANKE; PILLER, 2003). Alinhada a este objetivo, a CM incorpora esta tendência (PINE, 1993) e estuda qual é a melhor forma de integrar estes clientes para compreender suas necessidades individuais e traduzi-las em especificações dos produtos customizados (PILLER, 2004). No do contexto da CM, os clientes são integrados ao processo agregando valor ao produto, seja definindo, configurando, escolhendo, projetando ou mesmo modificando suas soluções anteriores para o produto (PILLER, 2004). A maior parte desta interação acontece durante o projeto do produto customizado para o cliente, sendo que para designar esta interação são utilizados os termos co-design(FRANKE; PILLER, 2003) e consumerinvolvement(JEPPESEN, 2005). Na CM, a participação do cliente pode ser conceituada como o processo que permite aos clientes expressarem seus requisitos e desenvolverem o produto a partir do mapeamentodos seus requisitos nas partes físicas do produto (FRANKE; PILLER, 2003; RANDALL et al, 2007). O resultado deste processo é um produto customizado com especificações que atendem as necessidades e desejos individuais do cliente, que por sua vez está disposto a pagar a mais por isto (PINE, 1993; FRANKE; PILLER, 2004; RANDALL et al, 2007; FRANKE et al, 2009; FRANKE et al, 2010).

Com a proposta de proporcionar esta integração do cliente, orientando o mapeamento de seus requisitos no produto foi desenvolvido o configurador de produto (PILLER, 2004). Seu conceito envolve uma ampla rede de interfaces entre cliente e empresa que assistem o cliente durante o processo de projeto, comparação de atributos e estimativas de custos para os pedidos de produtos customizados em massa (URBAN; HAUSER, 2004). Neste contexto, a função do configurador de produto é proporcionar ao cliente a interação necessária para mapear seus requisitos nas alternativas disponíveis do produto a fim de atender as suas necessidades.

\subsection{Configuradores de Produto}

Foram identificados diversos termos na literatura consultada para identificar o mecanismo utilizado para integrar o cliente no processo de CM (Figura 1). Os termos choicemenu, toolkits for masscustomization, e configuratorsão os mais frequentes. Apesar de o termo configurator também ser empregado relacionado aosoftware, é crescente a sua utilização vinculada ao configurador online de produto (LIETCHYet al, 2001). Entretanto, é importante salientar que o configurador de produto representa mais que uma ferramenta para combinar componentes modulares, podendo inclusive estar desassociada do software(FRANKE; PILLER, 2003). Em razão da crescente utilização da internetcomo meio da interação com o cliente, este termo passou a ser muito utilizado, por esta razão optou-se por utilizar a denominação 'configurador de produto' neste trabalho.Para denominar o configurador online de produto, os sites das empresas automobilísticas analisadas utilizam frequentemente o termo 'configurator'ou 'configure yourcar', mas também é 
comum o termo 'build yourcar'ou "monte seu carro", principalmente no mercado dos Estados Unidos e mercado Latino Americano, respectivamente.

\begin{tabular}{|l|l|}
\hline Nome & Autor \\
\hline Toolkits for user innovation & Franke; Piller, 2004; Jeppesen, 2005; Hippel, 2001 \\
\hline Toolkit for MC & $\begin{array}{l}\text { Franke } \text { et al, 2010; Franke et al, 2008; Piller, 2007; Franke, et al, 2009; } \\
\text { Piller, et al, 2005 }\end{array}$ \\
\hline Toolkits for customer co-design & Piller et al, 2004; Piller, 2004 \\
\hline Choice menu & Lietchy et al, 2001; Fogliatto; Da Silveira, 2008 \\
\hline Configuration toolkits & Franke; Piller, 2003 \\
\hline Configuration tool & Berger; Piller, 2003 \\
\hline MC configuration & Dellaert; Stremersch, 2005 \\
\hline User design & Randall et al, 2007 \\
\hline Choice Boards & Slywotzky, 2000 \\
\hline Co-design platforms & Oh et al, 2004 \\
\hline
\end{tabular}

Figura 1- Termos encontrados na literatura relacionados ao tema

No contexto do desenvolvimento de produto tradicional, as tecnologias de representação tridimensional e prototipagem proporcionam a equipe de projeto uma eficiente interação e aprendizado com o produto, resultando em melhorias na qualidade do projeto (ULRICH, 2010). No contexto de CM, este processo é parcialmente executado pelo cliente por meio do configurador de produto, sendo que uma de suas funções é reduzir o nível de conhecimento e habilidade necessários para o cliente realizar o projeto do produto (FRANKE et al, 2010). Este mecanismo ainda deve proporcionar o aprendizado sobre o produto, auxiliar o cliente no processo de 'projeto' além de incorporar o conceito da marca do produto (FRANKE; PILLER, 2003). Embora o cliente perceba que durante este processoesteja realizando o 'projeto' do produto (CHANG; CHEN, 2009), normalmente é realizada a configuração de produtos derivados por meio da combinação de módulos, não sendo realizadas atividades de projeto de componentes (SALVADOR; FORZA, 2004). Ao iniciar a configuração do produto, o cliente começa um processo de tentativa e erro para adequar as alternativas de customização as suas necessidades, este processo proporciona um maior conhecimento do produto e de suas reais necessidades (HIPPEL, 2001). O resultado desta interação é um produto projetado pelo próprio cliente, sendo que este processo também agrega valor ao produto e, conforme já mencionado, aumenta a disponibilidade do cliente pagar por isto (ULRICH, 2010; FRANKE et al, 2010).

Os configuradores online de produto podem variar muito em razão da sua complexidade, desde simples conjuntos de opções até sistemas complexos que permitem o processo de projeto (URBAN; HAUSER, 2004). Nos configuradores mais simples, somente são disponibilizadas a seleção de opções restritas (modelo, cor e características específicas), como o caso da Dell Computadores (www.dell.com.br). Os configuradores mais complexos permitem ao usuário uma participação mais ativa. Nestes configuradores de produto, o usuário possui maior liberdade, permitindo a inclusão de características não restritas às delimitadas pela empresa (FRANKE; PILLER, 2003). Um exemplo de um configurador mais elaborado é o caso loja de mobiliário alemã Huelsta, que disponibiliza inclusive um software associado ao configurador para o projeto dos produtos (www.huelsta.co.uk). No caso das empresas automobilísticas, é mais frequente a utilização de configuradoresonline de produtos em que são apenas disponibilizadas opções limitadas de alternativas, tais como cores, motorização, acabamento interno e opcionais, sendo que a participação 
do cliente está restrita em estabelecer a combinação destas alternativas de acordo com as suas necessidades. Entretanto, alguns configuradores online de produto disponibilizados pelas empresas automobilísticas permitem uma maior liberdade ao cliente na configuração do seu automóvel. Este é o caso do Mini Cooper, da fabricante BMW, que além de uma quantidade superior de alternativas para a composição do produto, permite a personalização do acabamento da pintura externa e do teto do veículo (http://www.miniusa.com). Apesar de se verificar outros exemplos na indústria automobilística, estes ainda são restritos e focalizados em nichos específicos de mercado.

Além de permitir a interação com o cliente, o configurador de produto também pode disponibilizar um maior conhecimento do comportamento do cliente por parte da empresa. O armazenamento das informações sobre as preferências do consumidor contribui para aumentar o aprendizado sobre as tendências de mercado, preferências dos clientes e os trade offsfeitos durante a configuração dos produtos (FOGLIATTO; DA SILVEIRA, 2008). A forma como o usuário interage com esta ferramenta é definida pela sua usabilidade (BEVAN, 2001). Esta usabilidade é obtida pela quantidade, combinação e qualidade dos recursos disponíveis nos configuradoresonline de produto. Estes recursos contidos nos configuradores expressam as informações disponíveis durante o processo de customização do produto, a facilidade de uso do configurador além de facilidades disponíveis para a configuração do produto. Desta forma, a combinação dos recursos disponíveis nos configuradores consiste em um importante fator para a sua usabilidade.

Apesar de existirem diversos estudos que abordam as vantagens comerciais da utilização do configurador online do produto como suporte à estratégia de CM(FRANKE; PILLER, 2004; CHANG; CHEN, 2009; FRANKE et al, 2009; FRANKE et al, 2010), estes estudos não indicam sob quais condições de mercado que esta estratégia é recomendada. A adoção da CM com o suporte do configurador onlineimplicano desenvolvimento de requisitos internos à empresa, principalmente relacionados ao desenvolvimento do produto, ao processo produtivo e a integração do cliente durante o processo de customização. Relacionado ao desenvolvimento de produto, recomenda-se um processo de desenvolvimento ágil (DURAYet al,2000; PILLER, 2004), com a adoção de uma arquitetura de produto modular (JOSE; TOLLENARE, 2005), sendo que o seu gerenciamento consiste em um dos desafios para a adoção da CM (SOSA et al, 2004). Quanto ao processo, destacam-se a utilizaçãodetecnologias de manufatura, tais como Computer Aided Manufacturing (CAM), Computer Integrating Manufacturing (CIM) e manufatura flexível (KOTHA, 1995; DA SILVEIRA et al, 2001). Como forma de integrar o cliente durante o processo de customização, a utilização do configurador de produto consiste em importante alternativa para realizar esta integração (PILLER, 2004). Além dos requisitos internos, questões do mercado também se apresentam importantes para viabilizar a adoção da CM com utilização do configurador. Neste sentido, além das condições já apresentadas por Pan e Holland (2006) relacionadas a demanda fragmentada, produtos com curto ciclo de vida e mercados maduros, Da Silveira et al (2001) mencionam a importância em se identificar a demanda do mercado pelo produto customizado e a capacidade de a estratégia de CM oferecer vantagem competitiva à empresa.

A industria automotiva tem por característicaatuar em mercados que apresentam os condicionantes de mercado para aplicar a estratégia de CM. Neste setor também se identifica a disponibilidade dos requisitos para a aplicação da CM com a utilização do configurador de produto. As empresas automobilísticas 
costumam possuir acesso as tecnologias de manufatura (RO et al, 2007), são reconhecidas por empregar técnicas avançadas de projeto de produto (CLARK; FUJIMOTO, 2001) e também por utilizar o configurador de produto. Apesar disto, algumas destas empresas automobilísticas têm por característica não utilizar a estratégia de CM com suporte do configurador de produto em alguns mercados. Apesar desta estratégia ser mencionada como vantajosa por diversos autores (CHANG; CHEN, 2009; FRANKE et al, 2009; FRANKE et al, 2010), os custos para a aplicação das tecnologias e as dificuldades de gerenciamento também se apresentam como empecilhos para o emprego da CM com a disponibilização do configurador de produto. Por esta razão, a forma e a intensidade como a empresa atuano mercado podem se apresentar como condições importantes para o emprego da CM com a utilização do configurador, principalmente por serem responsáveis em custear os requisitos internos da empresa necessários para utilizar a estratégia de CM. Como forma de representar esta atuação da empresa no mercado foram selecionadas três variáveis comerciais. A variável quantidade de carros vendidos procura identificar se o volume de vendas, e por consequencia, o impacto comercial destas vendas está associado a adoção desta estratégia. A variável dimensão do mercado tem por objetivo identificar se o volume total do mercado, ou seja, o potencial máximo de vendas para o produto, também está associado a esta decisão da empresa. Por fim, a variável variedade de modelos procura identificar se o tamanho do portfólio de produtos da empresa também está associado a utilização do configurador online de produto. O desdobramento do objetivo deste trabalho é apresentado em forma de hipóteses. A seguir são apresentadas as duas hipóteses que orientam a execução do trabalho.

$\mathrm{H} 1$ : As variáveis comerciais estão significativamente correlacionadas com o uso do configurador online do produto utilizado como suporte à estratégia de CM

Diversos autores já identificaram que a possibilidade de customizar produtos de acordo com a necessidade do cliente por meio de configuradores online de produto aumenta a sua disposição em pagar mais pelo produto (FRANKE; PILLER, 2004; CHANG; CHEN, 2009; FRANKE et al, 2009; FRANKE et al, 2010). Na indústria automobilística, as vendas de veículos não costumam ser realizadas por meio do configurador, mesmo assim diversas empresas o oferecem configurador como uma ferramenta comercial. A adoção do configurador online de produto, apesar de disseminada no setor automobilístico, ainda não representa unanimidade entre as empresas deste setor. O emprego daCMvinculada ao configurador pode estar associado ao comportamento de algumas questões relacionadas à atuação comercial da empresa. Estas questões são representadas pelo comportamento das variáveis comerciais quantidade de carros vendidos, dimensão do mercado e variedade de modelos. O estudo sobre esta hipótese contribui para compreender quais variáveis relacionadas à atuação da empresa no mercado devem ser analisadas e o nível de associação destas variáveis na decisão da empresa em utilizar o configurador online de produto como suporte à estratégia de CM.

$\mathrm{H} 2$-As variáveis comerciais analisadas estãosignificativamentecorrelacionadas com uma combinação específica de recursos que integram o configuradoronline de produto

Os configuradoresonlinede produtos utilizados pelas empresas automobilísticas possuem diferentes recursos. Estes recursos demonstram como o produto é apresentado para o cliente, quais são as opções de visualização, a presença de dicas para o cliente customizar o produto, informações atualizadas do preço da configuração entre muitas outras. É esperado encontrar diferenças entre os 
recursos presentes nos configuradores online disponibilizados pelas empresas automobilísticas. Entretanto, um configurador que possua disponível todos os recursos não é garantia de satisfação do cliente. Um excesso de alternativas frequentemente é percebido como negativo pelos clientes, principalmente em razão do aumento da complexidade e quantidade de informações (FRANKE; PILLER, 2003; CHANG; CHENG, 2009). A decisão da empresa por empregar a estratégia de CM com a disponibilização de um uma determinada combinação de recursos para integrar os configuradores pode estar associada com as questões relacionadas a atuação da empresa no mercado, representadas pelas variáveis comerciaisanalisadas. Dada a utilizaçãoda estratégia de CM com o suporte do configurador de produto, a comprovação desta hipótese contribui para identificar a existência e o nível de associação das variáveis comerciais com a combinação dos recursos que integram estes configuradores.

\section{MÉTODO DE PESQUISA}

Este trabalho é categorizado como uma pesquisa aplicada de natureza explicativa. Por meio de um levantamento e análise de dados relacionados aos configuradores online de produto disponibilizados pelas empresas automobilísticas este trabalho procura responder as hipóteses de pesquisa formuladas. Por esta razão também pode ser categorizado com uma abordagem quantitativa (GIL, 2002). O procedimento de coleta de dados e da seleção das variáveis analisadas é apresentado a seguir.

\subsection{Coleta de Dados}

A seleção da amostra das empresas automobilísticas iniciou com a busca sobre informações relacionadas ao desempenho comercial no mercado específico atendido pelo configurador online de produtos. Foram selecionadas empresas automobilísticas que possuem por característica disponibilizar modelos de automóveis com diversas opções, que atuam em diferentes segmentos de mercado simultaneamente, tais como: de carros pequenos, comerciais e de carros maiores, como vans ou sedans. Foram excluídas da amostra empresas que atuam em nichos diferenciados de mercado, como o caso das empresas Ferrari ou IVECO. O procedimento de coleta de dados seguiu cinco etapas apresentadas na Figura 2.

\begin{tabular}{|l|l|}
\hline Descrição da etapa & Fonte de dados \\
\hline $\begin{array}{l}\text { Identificar as variáveis comerciais (quantidade de carros vendidos e } \\
\text { dimensão do mercado) em um mercado específico. }\end{array}$ & $\begin{array}{l}\text { AnnualReport das empresas e relatório das } \\
\text { Associações Nacionais de Fabricantes de Veículos }\end{array}$ \\
\hline $\begin{array}{l}\text { Identificar a existência de site na internet da marca de automóvel no } \\
\text { respectivo mercado pesquisado }\end{array}$ & Internet \\
\hline $\begin{array}{l}\text { Identificar quais as empresas que disponibilizam configurador online } \\
\text { de produto em seu siteparacada mercado específico }\end{array}$ & $\begin{array}{l}\text { Página da marca de automóveis da empresa } \\
\text { destinada ao respectivo mercado }\end{array}$ \\
\hline $\begin{array}{l}\text { Identificar a quantidade de diferentes modelos disponibilizados pela } \\
\text { empresa em cada mercado }\end{array}$ & $\begin{array}{l}\text { Página da marca de automóveis da empresa } \\
\text { destinada ao respectivo mercado }\end{array}$ \\
\hline $\begin{array}{l}\text { Identificar os recursos dos configuradores online de produto de cada } \\
\text { marca no respectivo mercado. }\end{array}$ & $\begin{array}{l}\text { Página da marca de automóveis da empresa } \\
\text { destinada ao respectivo mercado }\end{array}$ \\
\hline
\end{tabular}

Figura 2 - Descrição das etapas executadas para a coleta de dados e respectivas fontes 
Alguns grupos automobilísticos não informaram a quantidade de automóveis vendidos por cada uma de suas marcas em cada mercado específico. Mesmo assim, as empresas automobilísticas que disponibilizaram a quantidade de veículos vendidos por marca em um determinado mercado e que possuem web sitetotalizaram 134 marcas de automóveis. Para cada uma destas marcas de automóvel que integrou a pesquisa, foi computada a quantidade de carros vendidos no mercado de abrangência do websiteda empresa. Utilizando como exemplo amarca de automóvel Fiat no Brasil, dada a presença dewebsiteorientado com informaçõesrestritasao mercado brasileiro, foi computada somente a quantidade de unidades vendidas pela marca Fiat na área de atuação do web site, neste caso no Brasil. O somatório do volume de vendas de todas as marcas de automóveis com web siteque integram a amostra deste estudo nos respectivos mercados de atuação dos web sitesanalisados corresponde ao montante de 20.441 .559 veículos vendidos no ano de 2008. Em razão da produção anual de automóveis durante o ano de 2008 atingir o montante de 52.637.206 unidades (OICA, 2008), as marcas em seus respectivos mercados analisados nesta pesquisa representam cerca de $38,83 \%$ da produção total de carros durante o ano de 2008.A descrição da amostra utilizada é apresentada na Tabela 1.

Tabela 1 - Descritivo da amostra utilizada na pesquisa

\begin{tabular}{l|l}
\hline Quantidade de grupos analisados (GM, PSA, Ford, Toyota, Volkswagen...) & 13 grupos \\
\hline $\begin{array}{l}\text { Quantidade de marcasanalisadas(GM- Chevrolet, Opel/Vauxhall, Holden, Saab; PSA- Peugeot, Citroen; Ford- } \\
\text { Ford, Lincon, Mercury, Volvo; Toyota- Toyota, Daihatsu, Lexus; Volkswagen- Volkswagen, Audi,...) }\end{array}$ & 25 marcas \\
\hline $\begin{array}{l}\text { Quantidade de mercados (países) com marcas analisadas } \\
\text { Somatório da quantidade de veículos vendidos pelas marcas no mercado de atuação do configurador de } \\
\text { produto analisado durante o ano de 2008 }\end{array}$ & $\begin{array}{l}20.441 .559 \\
\text { veículos vendidos }\end{array}$ \\
$\begin{array}{l}\text { Proporção da quantidade de vendas das marcas no mercado de atuação do configurador de produto } \\
\text { analisadoem relação à produção global de automóveis durante o ano de } 2008\end{array}$ & $38,83 \%$
\end{tabular}

\subsection{Recursos dos configuradores online de produto analisados}

A análise dos configuradores online de produto está restrita aos recursos contidos no processo de customização de produto disponibilizado no site de cada empresa. A seleção dos recursos a serem analisados partiu de uma iniciativa de levantamento de características diversas de configuradores online de produto disponibilizados por empresas dos mais variados segmentosdesenvolvida por pesquisadores sobre o tema (PILLERet al, 2010) e disponível no ConfiguratorDatabase(http://www.configurator-database.com)(Apêndice A). Nesta fonte são listadas 71 diferentes características dos configuradores online de produto, agrupadas em seis diferentes constructos (conceito/projeto, estrutura, especificações técnicas, visualização, pedidoe extras).

Uma análise prévia excluiu 12 características não relacionadas a recursos dos configuradores. Com isto foram analisados 60 recursos em uma amostra piloto composta por 20 configuradores onlinedisponibilizados pelas empresas automobilísticas. Nesta amostra, foi possível identificar que 12 recursos avaliam características semelhantes e foram agrupados, além destes, outros 3 dos recursos não foram avaliados em razão destas informações não estarem disponíveis nas páginas dos configuradores onlinedas empresas. Também foi possível identificar 
que outros 11 recursos não foram verificados na amostra de 20 configuradores online analisados. Destes recursos, 8 foram retirados da análise por não se adaptarem ao setor automobilístico e 3 foram mantidos, a saber: pedido online, informação da previsão de entrega do produto, e o prazo de entrega do produto. $\mathrm{Na}$ amostra analisada, foram identificados outros quatro recursos que não constavam no levantamento e foram incluídos na análise, como: simulação de financiamento, encaminhamento para um vendedor próximo e informações sobre o estoque do produto customizado. Ao final, foram selecionados para análise 41 recursos dos configuradores (Figura 3).

\begin{tabular}{|c|c|c|c|c|}
\hline & Recurso & Variável & Variável & Origem \\
\hline 1 & Botão de ajuda no configurador & presença/ausência & qualitativa & Config. Database \\
\hline 2 & Política de privacidade & presença/ausência & qualitativa & Config. Database \\
\hline 3 & Distância desde a página inicial até iniciar o configurador & $\begin{array}{l}\text { qtd.de páginas até iniciar o } \\
\text { configurador }\end{array}$ & quantitativa & Config. Database \\
\hline 4 & $\mathrm{O}$ acesso ao configurador está presente na metanavegação & presença/ausência & qualitativa & Automobilística \\
\hline 5 & Menu de perguntasfrequentes & presença/ausência & qualitativa & Config. Database \\
\hline 6 & Contatoparainformaçõesadicionais & presença/ausência & qualitativa & Config. Database \\
\hline 7 & Demonstrativo do processo de customização & presença/ausência & qualitativa & Config. Database \\
\hline 8 & Produtosprécustomizados (livraria) & presença/ausência & qualitativa & Config. Database \\
\hline 9 & Recomendações & presença/ausência & qualitativa & Config. Database \\
\hline 10 & Esquema de preço & presença/ausência & qualitativa & Config. Database \\
\hline 11 & Botão de "Voltar" & presença/ausência & qualitativa & Config. Database \\
\hline 12 & Modelobásicoparacustomização & presença/ausência & qualitativa & Config. Database \\
\hline 13 & Status do processo de Customização & presença/ausência & qualitativa & Config. Database \\
\hline 14 & Mapa das alternativas de customização & presença/ausência & qualitativa & Config. Database \\
\hline 15 & Guiaparacustomização & presença/ausência & qualitativa & Config. Database \\
\hline 16 & $\begin{array}{l}\text { Estrutura das decisões de customização no configurador } \\
\text { (passo a passo) }\end{array}$ & presença/ausência & qualitativa & Config. Database \\
\hline 17 & Preenchimentoautomático do sistema & presença/ausência & qualitativa & Config. Database \\
\hline 18 & Quantidade de etapas para configuração & qtd.deetapas para a configuração & quantitativa & Config. Database \\
\hline 19 & Resumo do produtocustomizado & presença/ausência & qualitativa & Config. Database \\
\hline 20 & Salvarconfiguração & presença/ausência & qualitativa & Config. Database \\
\hline 21 & Login & presença/ausência & qualitativa & Config. Database \\
\hline 22 & Pор up & presença/ausência & qualitativa & Config. Database \\
\hline 23 & Plug in & presença/ausência & qualitativa & Config. Database \\
\hline 24 & Visualização & presença/ausência & qualitativa & Config. Database \\
\hline 25 & Imagem final do produto customizado & presença/ausência & qualitativa & Config. Database \\
\hline 26 & Perspectivasfinais & $\begin{array}{l}\text { qtd.de perspectivas do produto } \\
\text { customizado }\end{array}$ & quantitativa & Config. Database \\
\hline 27 & Visualização final rotacionada (360graus) & presença/ausência & qualitativa & Config. Database \\
\hline 28 & Interatividade com o modelo final & presença/ausência & qualitativa & Config. Database \\
\hline 29 & Animação & presença/ausência & qualitativa & Config. Database \\
\hline 30 & Visualização do produto final ambientada & presença/ausência & qualitativa & Config. Database \\
\hline 31 & Custos dos itens (customizadores) individualizados & presença/ausência & qualitativa & Config. Database \\
\hline 32 & Botãocomprar & presença/ausência & qualitativa & Config. Database \\
\hline 33 & Pedidoonline & presença/ausência & qualitativa & Config. Database \\
\hline 34 & Forma de pagamento & presença/ausência & qualitativa & Config. Database \\
\hline 35 & O sistema informa a previsão de entrega do produto & presença/ausência & qualitativa & Config. Database \\
\hline 36 & Prazo de entrega do produto & qtd.de dias para a entrega & quantitativa & Config. Database \\
\hline 37 & Simulação de financiamento & presença/ausência & qualitativa & Automobilística \\
\hline 38 & Encaminhamento para um vendedor físico próximo & presença/ausência & qualitativa & Automobilística \\
\hline 39 & Encaminhamento da proposta online para avaliação & presença/ausência & qualitativa & Automobilística \\
\hline 40 & Informação de estoque de veículos & presença/ausência & qualitativa & Automobilística \\
\hline 41 & Fórum de discussão & presença/ausência & qualitativa & Config. Database \\
\hline
\end{tabular}

Figura 3 -Recursos dos configuradores onlinede produtos das marcas de automóveis analisadas

A partir da seleção dos 41 recursos dos configuradores ONLINE procedeu-se uma análise do comportamento destes recursos nos configuradores ONLINE que integram a amostra deste estudo. Foram avaliados todos os configuradores ONLINE das empresas que integram esta pesquisa. Em cada um dos configuradores avaliados foi analisado o comportamento de cada um dos 41 recursos que integram 
estes configuradores.Esta análise foi realizada entre o período de agosto a dezembro de 2010.

\section{RESULTADOS}

Os resultados são apresentados e discutidos de acordo com os objetivos da pesquisa desenvolvidos a partir das hipóteses apresentadas ao final da revisão de literatura. Primeiramente é apresentado o estudo sobre a associação entre as variáveis comerciais das empresas com a disponibilização do configurador online de produto como suporte à estratégia de $\mathrm{CM}$ e após, a associação destas variáveis comerciais com os recursos que integram estes configuradores.

\subsection{Identificar a correlação entre as variáveis comerciais com o uso do configurador online de produto utilizado como suporte à estratégia de CM}

O estudo confirma a tendência pela utilização do configurador onlinede produto como uma ferramenta comercial pelas empresas automobilísticas. Entre as 134 empresas analisadas, $78 \%$ disponibilizam o configuradorpara os clientes customizarem os produtos.A Tabela 02 apresenta uma análise descritiva das três variáveis comerciais analisadas. Uma análise prévia indica a existência de acentuada variação nas variáveis comerciais. Esta variação é resultado da diferença no volume de vendas entre os mercados consumidores de automóveis. Mesmo em um mercado mais homogêneo, como o europeu, verifica-se uma grande diferença no volume de unidades vendidas entre os países, que resulta nas variações apresentadas nas variáveis quantidade de carros vendidos e dimensão do mercado.

Tabela 1- Análise descritiva das variáveis comerciais das empresas com e sem configuradores online de produto

\begin{tabular}{l|c|c|c|c|c|c|c}
\hline \multirow{2}{*}{} & \multirow{2}{*}{$\mathrm{n}$} & \multicolumn{2}{|c|}{$\begin{array}{c}\text { Quantidade de Carros } \\
\text { Vendidos (x1.000) }\end{array}$} & \multicolumn{2}{c|}{$\begin{array}{c}\text { Dimensão do Mercado } \\
(\mathrm{x} 1.000)\end{array}$} & \multicolumn{2}{c}{ Variedade de Modelos } \\
\cline { 3 - 8 } & & Média & DPad & Méd. & DPad & Méd. & DPad \\
\hline Com configurador & 105 & 178,01 & 352,28 & $2.669,61$ & 3987,45 & 17,838 & 8,433 \\
\hline Semconfigurador & 29 & 60,19 & 57,170 & $1.065,76$ & 792,655 & 12,750 & 4,250 \\
\hline
\end{tabular}

Como forma de mensurar a associação entre as variáveis, foi realizada uma análise de correlação entre a variável presença/ausência do configurador onlinede produto e as variáveis comerciais. Em casos em que uma variável é quantitativa e outra qualitativa dicotômica, como no caso deste estudo, é recomendado aplicar a correlação point biserial $\left(r_{\mathrm{pb}}\right)$ (TATE, 1954;HAIRJUNIORetal, 2005), como apresentado na Tabela 3.

Tabela 2- Análise de correlação entre a presença do configurador online de produto e as variáveis comerciais (Point BiserialCorrelation - rpb)

\begin{tabular}{|c|c|c|c|c|}
\hline & & \begin{tabular}{|c|} 
Quantidade de Carros \\
Vendidos
\end{tabular} & $\begin{array}{l}\text { Dimensão do } \\
\text { Mercado }\end{array}$ & $\begin{array}{l}\text { Variedade de } \\
\text { Modelos }\end{array}$ \\
\hline $\begin{array}{l}\text { Disponibilização do } \\
\text { configurador online }\end{array}$ & $\begin{array}{l}\text { Point Biserial Correlation }\left(\mathrm{r}_{\mathrm{pb}}\right) \\
\text { Sig. (2-tailed) }\end{array}$ & \begin{tabular}{|c|}
0,18 \\
$0,039^{*}$
\end{tabular} & $\begin{array}{c}0,16 \\
0.013^{*}\end{array}$ & $\begin{array}{c}0.26 \\
0.002 *\end{array}$ \\
\hline
\end{tabular}


Foi identificada correlação significativa, ao nível de 5\%, entre a presença do configurador onlinede produto e as três variáveis comerciais. Apesar de se verificar uma correlação baixa, é possível constatar associação entre a utilização do configurador como suporte a estratégia de CM e as variáveis comerciais das empresas automobilísticas. Esta associação é verificada com a variável quantidade de carros vendidos pela empresa no respectivo mercado de utilizaçãodo configurador de produto $\left(r_{p b} 0,18 ; p=0,039\right)$, com o total de carros vendidos no mercado ao qual o configurador está sendo disponibilizado (dimensão do mercado) $\left(r_{p b} 0,16 ; p=0,013\right)$ e com a variedade de modelos que a empresa está disponibilizando neste mercado $\left(r_{p b} 0,26 ; p=0,002\right)$. Em razão das correlações positivas verificadas e significativas $(p<0,05)$, este resultado sugere que a intensidade de atuação no mercado, representada pelo comportamento das três variáveis comerciais analisadas, possui efeito na decisão da empresa disponibilizar o configurador onlinede produto como suporte à estratégia de CM. Apesar de se identificar um nível de correlação baixo, a variável comercial variedade de modelos, que representa o tamanho do portfólio de carros da empresa automobilística, é a que possui maior correlação positiva entre as variáveis analisadas. Este resultado sugere a importância dada ao tamanho portfólio de produtos das empresas automobilísticas na decisão da empresa em disponibilizar o configurador onlinede produto. Os resultados verificados confirmam a Hipótese 1.

\subsection{Identificar a correlação entre as variáveis comerciais com uma combinação específica de recursos que integram o configurador online de produto}

Entre as empresas que disponibilizam o configurador foram analisados 41 recursosque integram os configuradores (Figura 3).Em razão da quantidade de recursos analisados nos configuradores optou-se por analisá-los de forma conjunta, agrupando os configuradores de acordo com a similaridade de seus recursos. Com este objetivo foi utilizada a técnica estatística multivariada análise de agrupamentos (clusteranalysis). Esta técnica tem por objetivo agregar observações de acordo com suas características, resultando em grupos com homogeneidade interna e heterogeneidade externa (HAIR JUNIOR etal, 2005).

Em função da natureza dos recursos dos configuradores, expressos principalmente por variáveis categóricas (38), mas também por quantitativas (3) (Figura 3) foi empregada a técnica de análise de agrupamentos 'twostep', que tem por característica viabilizar o agrupamento das observações com variáveis categóricas e métricas de forma simultânea. Em razão da quantidade excessiva de variáveis (41), selecionou-se o algoritmo 'Schwarz'sBayesianCriterion' para a seleção dos agrupamentos, visto que este algoritmo penaliza a entrada de variáveis no modelo, reduzindo problemas de um modelo com muitas variáveis (overfitting). A quantidade de agrupamentos é dada pelo menor valor obtido para BayesianInformationCriterion (BIC), sendo que o menor valor de BIC obtido foi para 
dois agrupamentos. Entre os 105 configuradores onlineanalisados de acordo com 41 recursos foram encontrados dois padrões de configuradores. Estes padrões foram denominados como 'padrão básico A', com 46 observações, e 'padrão avançado B', com 59 observações.

A partir da definição dos padrões foi possível verificar quais recursos dos configuradores são mais discriminadores entre estes padrões. Para as 38 variáveis categóricas foi realizado um teste qui quadrado para verificar diferenças significativas entre a frequência dos recursos dos configuradores em cada padrão (Tabela 4). Para as 3 variáveis métricas foi realizado um teste não paramétrico de diferença de médias (Tabela 5). Os resultados verificados para cada um dos recursos é apresentado na íntegra no Apêndice $A$.

Tabela 3 - Frequênciasdosrecursos dos configuradores de produto com diferença significativa entre o padrão básico $A$ e o padrão avançado $B$ de configuradores (teste qui quadrado)

\begin{tabular}{|c|c|c|c|c|}
\hline & Recurso do configurador & $\begin{array}{c}\text { Padrão 'básico } \\
\text { A' }\end{array}$ & Padrão 'B' & $\begin{array}{l}\text { Resultado } \\
\text { (P-value) }\end{array}$ \\
\hline 4 & $\mathrm{O}$ acesso ao configurador está presente na metanavegação & $9_{(-7,7)}^{14,1 \%}$ & $55_{(7,7)}^{85,9 \%}$ & $p<0,000 * *$ \\
\hline 5 & Menu de perguntasfrequentes & $16_{(5)}{ }^{64 \%}$ & $9_{(-5)}^{36 \%}$ & $p=0,020 *$ \\
\hline 9 & Recomendações & $5_{(-3,4)}^{17,2 \%}$ & $24_{(3,4)}^{82,8 \%}$ & $p=0,001 * *$ \\
\hline 10 & Esquema de preço & $34_{(-3,4)} 37,4 \%$ & $57_{(3,4)}^{62,6 \%}$ & $p=0,001 * *$ \\
\hline 13 & Status do processo de customização & $43_{(-2,9)} 42,2 \%$ & $59_{(2,9)} 57,7 \%$ & $p=0,047^{*}$ \\
\hline 14 & Mapa das alternativas de customização & $42_{(-2,3)}^{41,6 \%}$ & $59_{(2,3)} 58,4 \%$ & $p=0,021^{*}$ \\
\hline 19 & Resumo do produtocustomizado & $34_{(-3,4)} 34,4 \%$ & $57_{(3,4)} 62,6 \%$ & $p=0,001 * *$ \\
\hline 20 & Salvarconfiguração & $10_{(-2,1)}^{29,4 \%}$ & $24_{(2,1)}{ }^{70,6 \%}$ & $p=0,040^{*}$ \\
\hline 21 & Login & $2_{(-2,2)}^{15,4 \%}$ & $11_{(2,2)}^{84,6 \%}$ & $p=0,027^{*}$ \\
\hline 22 & Pop up & $0_{(-2,9)} 0^{0} \%$ & $10_{(2.9)}^{100 \%}$ & $p=0,003 *$ \\
\hline 25 & Imagem final do produto customizado & $33_{(-3,0)} 37,5 \%$ & $55_{(3,0)} 62,5 \%$ & $p=0,003^{*}$ \\
\hline 27 & Visualização final rotacionada (360graus) & $3_{(-2,0)} 20 \%$ & $12_{(2,0)}^{80 \%}$ & $p=0,045^{*}$ \\
\hline 31 & Custos dos itens (customizadores) individualizados & $27_{(-4,0)}^{33,3 \%}$ & $54_{(4,0)} 66,7 \%$ & $p<0,000^{* *}$ \\
\hline \multicolumn{5}{|c|}{ Freqüência(resíduo ajustado) ${ }^{\text {freqüência percentual }}$} \\
\hline
\end{tabular}

Tabela 4- Diferença de médias dos recursos dos configuradores de produto com diferença significativa entre o padrão básico $A$ e o padrão avançado $B$ de configuradores (teste U Mann-Whitney)

\begin{tabular}{c|l|c|c|l}
\hline & Recurso do configurador & Padrão 'A' & Padrão 'B' & P-value \\
\hline 3 & Distância desde a página inicial até iniciar o configurador & $\bar{X}=3,48$ & $\bar{X}=2,42$ & $p<0,000^{* *}$ \\
\hline 18 & Quantidade de etapas para configuração & $\bar{X}=4,83$ & $\bar{X}=5,97$ & $p<0,000^{* *}$ \\
\hline 26 & Perspectivasfinais & $\bar{X}=1,63$ & $\bar{X}=3,19$ & $p<0,000^{* *}$ \\
\hline
\end{tabular}

* significativo a $5 \%$ - **significativo a $1 \%$

Entre os 41 recursos dos configuradores analisados foi identificada diferença significativa, ao nível de $5 \%$, para 16 recursos entre os padrões de configuradores ' $A$ ' e ' $B$ ' (Tabelas 5 e 6). Os resultados indicam que o primeiro agrupamento, 0 Padrão ' $A$ ' de configurador, apresenta uma menor frequência em 13 recursos qualitativos dos configuradores, tais como esquema de preço atualizado do produto conforme a customização (item 10), custos dos itens individualizados (item 31), presença do configurador no menu da metanavegação do site(item 4), entre outros. Enquanto isto, as empresas que disponibilizam o Padrão ' $\mathrm{B}$ ' de configurador possuem uma frequência superior destes mesmos recursos (Tabela 4). Nos 3 recursos dos configuradores quantitativos analisados, foi verificado que as empresas que disponibilizam o padrão ' $A$ " apresentam em média o configurador mais afastado 
da página inicial do site(item 3), uma menor quantidade de etapas para configuração do produto (item 18) e uma menor quantidade de perspectivas finais do produto customizado (item 26) em relação ao padrão 'B' (Tabela 5).

A partir destes resultados, pode-se identificar a existência de dois diferentes padrões de configuradores onlinedeproduto utilizados pelas empresas automobilísticas. Um padrão mais simples, com menor quantidade de recursos, denominado Padrão Básico (A), e um mais completo, com mais opções disponíveis ao cliente durante o processo de customização de produto online, denominado Padrão Avançado (B).

Uma análise descritiva das variáveis comerciais analisadas de acordo com as empresas que adotam um padrão básico ' $A$ ' e o padrão avançado ' $B$ ' é apresentadana Tabela 6 . Verifica-se que a média da variável quantidade de carros vendidose dimensão de mercado entre as empresas que disponibilizam o configurador de produto avançado (B)éaparentemente superior que entre as empresas que adotam o padrão básico $(A)$.

Tabela 5 - Análise descritiva das variáveis comerciais das empresaspara os dois padrões de configuradores online de produto

\begin{tabular}{l|c|c|c|c|c|c|c}
\hline & \multirow{2}{*}{$\mathrm{n}$} & \multicolumn{2}{|c|}{$\begin{array}{c}\text { Quantidade de carros } \\
\text { vendidos (x1.000) }\end{array}$} & \multicolumn{2}{c|}{$\begin{array}{c}\text { Dimensão do mercado } \\
(\mathrm{x} 1.000)\end{array}$} & \multicolumn{2}{c}{ Variedade de modelos } \\
\cline { 3 - 8 } & & Média & DPad & Média & DPad & Média & DPad \\
\hline PadrãoBásico 'A' & 46 & 107,14 & 151,521 & 1418,51 & 2000,89 & 17,086 & 8,309 \\
\hline PadrãoAvançado'B' & 59 & 233,27 & 442,709 & 3645,05 & 4795,74 & 18,423 & 8,484 \\
\hline
\end{tabular}

Para identificara associação entre as variáveis comerciais e a decisão da empresa em utilizar a estratégia de CM com a disponibilização do configurador onlinede produto com o padrão avançado de recursos foi realizada uma análise de correlação entre a variável presença/ausência do configurador onlinede produto avançado (B) e as variáveis comerciais, seu resultado é apresentado na Tabela 7.

Tabela 6- Análise de correlação entre a presença do configurador online de produto do padrão avançado (B) e as variáveis comerciais (Point BiserialCorrelation $-r_{\mathrm{pb}}$ )

\begin{tabular}{|c|c|c|c|c|}
\hline & & $\begin{array}{c}\text { Quantidade de carros } \\
\text { Vendidos }\left(\mathrm{y}_{1}\right)\end{array}$ & $\begin{array}{l}\text { Dimensão do } \\
\text { Mercado }\left(\mathrm{y}_{2}\right)\end{array}$ & $\begin{array}{l}\text { Variedade de } \\
\text { Modelos }\left(\mathrm{y}_{3}\right)\end{array}$ \\
\hline $\begin{array}{l}\text { Disponibilização do configurador } \\
\text { online de produto no padrão } \\
\text { avançado (B) }\end{array}$ & $\begin{array}{l}\text { Point Biserial Correlation }\left(\mathrm{r}_{\mathrm{pb}}\right) \\
\text { Sig. (2-tailed) } \\
\mathrm{n}\end{array}$ & $\begin{array}{c}0.22 \\
0.027^{*} \\
105\end{array}$ & $\begin{array}{l}0.28 \\
0.004 * * \\
105\end{array}$ & $\begin{array}{c}0.08 \\
0.425 \\
105\end{array}$ \\
\hline
\end{tabular}

* significativo a $5 \%$ - ** significativo a $1 \%$

Foi identificada correlação significativa $(p<0,05)$ entre a presença do configurador onlinede produto avançado e as variáveis quantidade de carros vendidos e dimensão do mercado. Apesar da correlação identificada não ser alta, este resultado evidencia a associação entre as variáveis quantidade de carros vendidos e dimensão de mercado e a disponibilização do configurador onlinede produto com o padrão avançado de recursos (B) como suporte a estratégia de $\mathrm{CM}$. A correlação entre o padrão avançado de configurador $(B)$ e a variável dimensão de mercado( $r_{p b}$ 0,28; $\left.p=0,004\right)$ indica que a abrangência do mercado de atuação do configurador está associada ao uso de um configurador com um padrão superior de recursos. A correlação do padrão avançado de configurador com a variável quantidade de carros vendidos $\left(r_{p b} 0,22 ; p=0,027\right)$ indica que não apenas a 
disponibilização do configurador onlinede produto, mas também a combinação de seus recursos está associada à venda de veículos.

Entre os 41 recursos dos configuradores analisados, o padrão avançado de configurador (B) é integrado por 40 recursos em melhores condições que o padrão básico de configurador. Entre os 37 recursos qualitativos analisados, o padrão avançado somente não possui a presença do recurso menude perguntas frequentes (item 5daTabela 4). Nos recursos quantitativos analisados, o padrão avançado de configurador possui uma melhor condição para todos, apresentando uma menor distância do configurador desde a página inicial (item 3), uma maior quantidade de etapas de configuração (item 18) e um maior número de perspectivas do produto customizado (item 26) (Tabela 5). De acordo com Chang e Cheng (2009), o excesso de recursos nos configuradores normalmente resulta em uma sobrecarga de informações e uma percepção de maior complexidade no processo por parte do cliente. Este resultado é um indicativo de que a composição dos recursos do configurador do tipo avançado para as empresas automobilísticas, identificado nesta pesquisa, ainda não prejudica a interação com o cliente, e por consequência, a efetividade da ferramenta. Esta combinação de recursos com maior associação com a venda de veículos contribui para complementar os métodos para projeto de configuradores de produto (LIETCHY etal, 2001; FOGLIATTO; DA SILVEIRA, 2008), visto que estes métodos não incorporam a seleção da melhor combinação de recursos dos configuradores em seu projeto.

A variável variedade de modelos, que representa o tamanho do portfólio de produtos das empresas, não se apresentou com associação significativa $\left(r_{p b} 0,08\right.$; $p=0,425)$ com as empresas que disponibilizam o configurador online do padrão avançado como suporte à estratégia de CM. Desta forma, somente as variáveis quantidade de carros vendidos e dimensão do mercado possuem associação a disponibilização do configurador com padrão avançado de recursos. Este resultado sugere a importância de análise das condições de mercado referentes a estas variáveis como forma de identificar a opção por um configurador com uma quantidade superior de recursos.

Foi verificada correlação significativa, ao nível de 5\%, $(p=0,027 ; p=0,004)$ de duas das variáveis comerciais analisadas, quantidade de carros vendidos e dimensão do mercado, com a utilização do configurador de produto do padrão avançado de recursos. Este resultado contribui para ressaltar a importância destas variáveis na decisão da empresa em optar por disponibilizar o configurador como suporte estratégia de $\mathrm{CM}$. Em razão da ausência de associação com a variável comercial variedade de modelos a Hipótese 2 foi parcialmente confirmada.

\subsection{Síntese dos resultados}

De acordo com 134 empresas automobilísticas amostradas neste estudo, com vendas nos mercados analisados correspondentes a $38,83 \%$ da produção de veículos durante o ano de 2008, foi possível confirmar a Hipótese 1 e parcialmente a Hipótese 2. Entre estas empresas analisadas, 105 destas possuem configurador onlinede produto em sua página na internet. Foi possível identificar uma associação significativa, ao nível de $5 \%$, da disponibilização do configurador onlinede produto com as três variáveis comerciais estudadas (quantidade de carros vendidos, dimensão do mercado e variedade de modelos). Este resultado sugere a importância 
de análise das condições mercadológicas, representadas pelas três variáveis comerciais analisadas, na decisão da empresa automobilística em disponibilizar o configurador de produto como suporte à estratégia de CM.

Entre as 105 empresas automobilísticas que disponibilizam o configurador onlinede produto, foi possível identificar 2 padrões distintos, um básico, com menos recursos e outro avançado, com uma maior quantidade de recursos. Entre estas empresasautomobilísticasquedisponibilizamoconfigurador, 46 destas possuem configurador do padrão básico e 59 do tipo avançado. As empresas que disponibilizam configurador de produto do tipo avançado estão associadas a uma maior quantidade de carros vendidos e a mercados mais numerosos. Os resultados comprovam a correlação significativa, ao nível de $5 \%$, do configurador onlinede produto, e da combinação dos seus recursos, com a venda de veículos. Dada a opção por disponibilizar o configurador como suporte à estratégia de CM, este resultado indica a importância em avaliar as variáveis quantidade de carros vendidos e a dimensão do mercado ao decidir por disponibilizar uma combinação mais completa de recursos.A síntese dos resultados encontrados é apresentada na Figura 4.

\begin{tabular}{|c|c|c|}
\hline Objetivos & Confirmação & Resultados encontrados \\
\hline \multirow{3}{*}{$\begin{array}{l}\text { Identificar a correlação entre as } \\
\text { variáveis comerciais com o uso do } \\
\text { configurador online de produto } \\
\text { utilizado como suporte à estratégia } \\
\text { de CM }\end{array}$} & \multirow{3}{*}{$\operatorname{sim}$} & $\begin{array}{l}\text { - As empresas automobilísticas que disponibilizam o configurador online de } \\
\text { produto como suporte à estratégia de CMpossuem em média maior quantidade } \\
\text { de veículos vendidos, estão localizadas em mercados maiores e possuem uma } \\
\text { maior variedade de modelos disponíveis. }\end{array}$ \\
\hline & & $\begin{array}{l}\text { - Correlação significativa, ao nível de } 5 \% \text {, com a utilização do configurador } \\
\text { online de produto como suporte à estratégia de CM com as variáveis quantidade } \\
\text { de carros vendidos, dimensão do mercado e variedade de modelos. }\end{array}$ \\
\hline & & $\begin{array}{l}\text { - As variáveis comerciais analisadas se apresentam importantes na decisão da } \\
\text { empresa em disponibilizar o configurador online de produto como suporte à } \\
\text { estratégia de CM. }\end{array}$ \\
\hline \multirow{3}{*}{$\begin{array}{l}\text { Identificar a correlação entre as } \\
\text { variáveis comerciais com uma } \\
\text { combinação específica de recursos } \\
\text { que integram o configurador } \\
\text { online de produto }\end{array}$} & \multirow{3}{*}{ parcial } & $\begin{array}{l}\text { - As empresas automobilísticas que disponibilizam o configurador online de } \\
\text { produto com maior quantidade de recursos (tipo avançado) possuem em média } \\
\text { maior quantidade de veículos vendidos e estão localizadas em mercados } \\
\text { maiores. }\end{array}$ \\
\hline & & $\begin{array}{l}\text { - Correlação significativa,ao nível de } 5 \% \text {, das empresas automobilísticas que } \\
\text { disponibilizam o configurador online de produto com maior quantidade de } \\
\text { recursos (tipo avançado) como suporte à estratégia de CM com as variáveis } \\
\text { quantidade de carros vendidos e dimensão do mercado. }\end{array}$ \\
\hline & & $\begin{array}{l}\text { - Dada a opção por disponibilizar o configurador online de produto, as variáveis } \\
\text { quantidade de carros vendidos e dimensão do mercado se apresentam } \\
\text { importantes na decisão por uma combinação mais completa dos recursos a } \\
\text { integrar o configurador de produto. }\end{array}$ \\
\hline
\end{tabular}

Figura 4 - Síntese dos resultados encontrados

\section{CONCLUSÕES}

Por meio de uma amostra de 134 configuradores onlinede produtos de empresas automobilísticas foi identificada correlação significativa, ao nível de $5 \%$, entre disponibilização do configurador utilizado como suporte à estratégia de CM com as três variáveis comerciais analisadas. Entre as 105 empresas que dispunham de configuradores online, foi possível identificar 2 padrões distintos de acordo com os recursos destes configuradores, um básico e outro avançado. Dada a opção da empresa pela utilização da estratégia de CM com a disponibilização do configurador, foi verificadacorrelaçãosignificativa, ao nível de $5 \%$, com uma superior combinação 
de recursos que integram os configuradores com as variáveis quantidade de carros vendidos e dimensão do mercado.

A viabilidade da utilização da estratégia de CM implica na avaliação das condições de mercado (PAN; HOLLAND, 2006; DA SILVEIRA etal, 2001) e na disponibilidade de requisitos internos de produção (KOTHA, 1995; DA SILVEIRA etal, 2001), de desenvolvimento de produto (DURAYetal, 2000) e integração do cliente (PILLER, 2004; FRANKE etal, 2010). Além destas questões, este trabalho contribui para ressaltar a necessidade de avaliar a forma como a empresa atua neste mercado. Neste sentido, as variáveis comerciais quantidade de carros vendidos, dimensão do mercado e variedade de modelos se apresentaram importantes para se decidir pelo uso do configurador onlineassociado à estratégia de CM.

Os resultados indicam a importância de análise das variáveis comerciais analisadas na decisão da empresa em utilizar a estratégia de CM vinculada ao configurador onlinede produto, assim como de qual combinação dos recursos a integrarem este configurador. A partir dos resultados encontrados, sugere-se como trabalhos futuros estudos sobre o efeito dos requisitos internos da empresa para a adoção da estratégia de CM com a utilização do configurador, tais como: FMS, CAM, modularidade, plataforma de produto entre outros e a modelagem das variáveis comerciais que afetam a decisão da empresa em utilizar a estratégia de CM com a disponibilização do configurador onlinede produto.

\section{AGRADECIMENTOS}

A realização deste trabalho obteve apoio financeiro do Estado do Rio Grande do Sul, por intermédio da FAPERGS (PqG nº 06/2010 - 1008530).

\section{REFERÊNCIAS}

BARDAKCI, A.; WHITELOCK, J. How "ready" are customers for mass customization? An exploratory investigation.European Journal of Marketing, v.38, n.11/12, p.1396-1416, 2004.

BARE, M.; COX, J. J. Applying principles of mass customization to improve the empirical product development process. Journal of Intelligent Manufacturing, v.19, n.5, p.565-576, 2008.

BERGER, C.; PILLER, F. Customers as co-designers.IEE Manufacturing Engineer, p.42-45, August/September 2003.

BEVAN, N. International Standards for $\mathrm{HCl}$ and Usability.International Journal of Human-Computer Studies, v.55, n.4, p. 533-552, October 2001.

CLARK, K. B.; FUJIMOTO, T. Product development performance: strategy, organization and management in the world auto industry. Boston: Harvard Business School Press, 1991. 
CHANG, C.C.; CHEN, H.Y. I Want My Own Way, But Which Way? The effects of different product categories and cues on customer responses to web-based customizations.Cyber Psychology \& Behavior, v.12, n.1, p.7-14, 2009.

DA SILVEIRA, G.; BORENSTEIN, D.; FOGLIATTO, F. S. Mass customization: literature review and research directions. International Journal of Production Economics, v.72, n.1, p.1-13, 30 June 2001.

DAVIS, S. Future Perfect. 1. ed. Reading: Addison Wesley P, 1987.

DELLAERT, B. G. C.; Stremersch, S. Marketing mass-customized products: striking a balance between utility and complexity. Journal of Marketing Research, v.42, p.219-227, May 2005.

DURAY, R.; WARD, P. T.; MILLIGAN, G. W.; BERRY, W. L. Approaches to mass customization: configurations and empirical validation. Journal of Operations Management, v.18, n.6, p.605-625, November 2000.

FANG, E. E. Customer Participation and the Trade-Off between New Product Development Innovativeness and Speed to Market.Journal of Marketing, v.72, p.90104 , July 2008.

FOGLIATTO, F. S.; DA SILVEIRA, G. J. C. Mass customization: a method for market segmentation and choice menu design. International Journal of Production Economics, v.11, n.2, p.602-622, February 2008.

FRANKE, N.; KEINZ, P.; SCHREIER, M. Complementing mass customization tookits with user communities: how peer input improves customer self-design. Journal of Product Innovation Management, v.25, n.6, p.546-559, November 2008.

FRANKE, N.; KEINZ, P.; STEGER, C. Testing the Value of Customization: When Do Customers Really Prefer Products Tailored to their Preferences?.Journal of Marketing, v.73, p.103-121, September 2009.

FRANKE, N.; PILLER, F. T. Key reserch issues in user interaction with configuration toolkits in mass customisation. The International Journal of Technology Management, v.25, n.5/6, p.578-599, 2003.

FRANKE, N.; PILLER, F. T. Value creation by toolkits for user innovation and design: the case of the watch market. Journal of Product Innovation Management, v.21, n.6, p.401-415, 2004.

FRANKE, N.; SCHREIRER, M.; KAISER, U.The "I designed it myself" effect in mass customization.Management Science, v.56, n.1, p.125-140, January 2010.

FRUTOS, J. D.; BORENSTEIN, D.A framework to support customer-company interaction in mass customization enviroments.Computer in Industry, v.54, n.12, p.115-135, June, 2004. 
GIL, A. C. Como elaborar projetos de pesquisa. São Paulo: Ed. Atlas, 2002.

GILMORE, J. H.; PINE, B. J. I. The four faces of mass customisation. Harvard Business Review, v.75, n.1, p.91-101, 1997.

HAIR JUNIOR, J.F.; ANDERSON, R.E.; TATHAM, R.L.; BLACK, W.C. Multivariate Data Analysis. 5th ed. New Jersey: Prentice Hall, 2005.

HART, C. W. L. Mass customization: conceptual underpinnings, opportunities and limits. International Journal of Service Industry Management, v.6, n.2, p.36-45, 1994.

HIPPEL, E. V. Perspective: user toolkits for innovation. Journal of Product Innovation Management, v.18, p.247-257, 2001.

JEPPESEN, L. B. User toolkits for innovation: consumers support each other. Journal of Product Innovation Management, v.22, p.347-362, 2005.

JOSE, A.; TOLLENARE, M. Modular and plataform methods for product family design: literature analysis. Journal of Intellingent Manufacturing, v.16, n.3, p.371-390, 2005.

KOTHA, S. Mass customization: implementing the emerging paradigm for competitive advantage. Strategic Management Journal, v.16, p.21-42, Summer, 1995.

LIETCHY, J.; RAMASWAMY, V.; COHEN, S. H. Choice menus for mass customization: An experimental approach for analyzing customer demand with an application to a web-based information service. Journal of Marketing Research, v.38, p.183-196, May 2001.

MCKENNA, R. Marketing in an Age of Diversity. In: Gilmore, J. H.; Pine II, J. B. Markets of One: creating customer-unique value through mass customization.1.ed. Boston: Harvard Business School Press, 2000.

OGAWA, S.; PILLER, F. T. Reducing the risks of new product development.MIT Sloan Management Review, v. 47, n. 2, p.65-71, Winter, 2006.

$\mathrm{OH}, \mathrm{H}$.; YOON, S.; HAWLEY, J. What virtual reality can offer to the furniture industry.Journal of Textile and Apparel, Technology and Management, v.4, n.1, Summer, 2004.

OICA.Production Statistics.International Organization of Motor Vehicle Manufacturers, 2008.Disponivel em: <http://oica.net/category/production-statistics/>. Acesso em: 25 Fevereiro 2010.

PAN, B.; HOLLAND, R.A mass customised supply chain for the fashion system at the design-production interface.Journal of Fashion Marketing and Management, v.10, n.3, p.345-359, 2006. 
PILLER, F.; SCHUBERT, P.; KOCH, M.; MOESLEIM, K.From Mass Customization to Collaborative Customer CoDesign.Proceedings... 13th European Conference on Informations Systems (ECIS). Turku, Finland, 2004. Disponívelemhttp://aisel.aisnet.org/ecis2004/118

PILLER, F.; SCHUBERT, P.; KOCH, M.; MÖSLEIN, K. Overcoming Mass Confusion: Collaborative Customer Co-Design in Online Communities. Journal of ComputerMediated Communication, v.10, n.4, p.1-25, 2005.

PILLER, F. T. Mass customization: reflections on the state of the concept. International Journal of Flexible Manufacturing Systems, v.16, n.4, p.313-334, October 2004.

PILLER, F. T. Observations on the present and future os mass customization.International Journal of Flexible Manufacturing Systems, 19, n. 4, December 2007.

PILLER, F.; FRANKE, N.; TSENG, M. E.; HVAM, L. Configurator Database.Disponívelem<http://www.configurator-database.com>, acessadoem $8 / 10 / 2010$

PILLER, F. T.; MOESLEIN, K.; STOKO, C. Does Mass Customization Pay? An Economic Approach to Evaluate Customer Integration.Production Planning \& Control, v.15, n.4, p.435-444, June 2004.

PINE II, J. B. Mass customization: the new frontier in business competition. 1. ed. Cambridge: Harvard Business Review, 1993.

RANDALL, T.; TERWIESCH, C.; ULRICH, K. T. User design of customized products.Marketing Science, v.26, n.2, p.268-280, 2007.

RO,Y. K.;LIKER, J. K.; FIXSON. Modularity as a Strategy for Supply Chain Coordination: The Case of U.S. Auto. IEEE Transactions on Engineering Management, v.54, n.1, p.172-189, 2007.

SALVADOR, F.; FORZA, C.; RUNGTUSANATHAM, M.Modularity, product variety, production volume, and component sourcing: theorizing beyond generic prescriptions. Journal of Operations Management, v.20, n.5, p.549-575, September 2002.

SALVADOR, F.; FORZA, C. Configuring Products to Address the CustomizationResponsiveness Squeeze: A survey of management issues and opportunities. International Journal of Production Economics, v,91, n.3, p.273-291, 2004.

SIMONSON, I. Determinants of Customers' Responses to Customized Offers: Conceptual Framework and Research Propositions.Journal of Marketing, v.69, p.3245, Jannuary 2005. 
SOSA, M.E.; EPPINGER, S.D.; ROWLES, C.M.The Misalignment of Product Architecture and Organizational Structure in Complex Product Development.Management Science, v.50, n.12, p.1674-1689, December 2004.

SLYWOTZKY, A. J. The age of the choiceboard.Harvard Business Review, p.40-41, 2000.

TATE, R. F. Correlation between a discrete and a continuous variable: point biserial correlation. Annals of Mathematical Statistics, n.2, p.603-607, 1954.

TSENG, M. M.; DU, X. Design by customers for mass customization products.Annals... International Academy for Production Engineering (CIRP), v.47, n.1, p.103-106, 1998.

ULRICH, K. T. Users, Experts, and Institutions in Design. In: Ulrich, K. T. Design: creation of artifacts in society. noprelo. ed.: Pontifica Press, 2010.

URBAN, G. L.; HAUSER, J. R. Listening in to find and explore new combinations of customer needs. Journal of Marketing, v.68, p.72-87, April 2004.

\section{APÊNDICE}

APÊNDICE A

\begin{tabular}{|c|c|c|c|}
\hline & & Situação & Variável \\
\hline \multicolumn{4}{|c|}{ Constructo - Conceito/Projeto } \\
\hline 1 & Logomarca para o configurador & $\begin{array}{l}\text { constante na amostra } \\
\text { (ausente) }\end{array}$ & presença/ausência \\
\hline 2 & Botão de ajuda no configurador & analisado & presença/ausência \\
\hline 3 & Politica de privacidade & analisado & presença/ausência \\
\hline 4 & $\begin{array}{l}\text { Termos e Condições de acesso } \\
\text { disponíveis na metanavegação }\end{array}$ & analisado no item 3 & presença/ausência \\
\hline 5 & Menu de perguntas frequentes & analisado & presença/ausência \\
\hline 6 & $\begin{array}{l}\text { Contato para informações } \\
\text { adicionais }\end{array}$ & analisado & presença/ausência \\
\hline 7 & $\begin{array}{l}\text { Distância desde a página inicial } \\
\text { até iniciar o configurador }\end{array}$ & analisado & qtd. páginas desde a inicial até o configurador \\
\hline \multicolumn{4}{|c|}{ Constructo - Estrutura } \\
\hline 8 & $\begin{array}{l}\text { Demonstrativo do processo de } \\
\text { customização }\end{array}$ & analisado & presença/ausência \\
\hline 9 & $\begin{array}{l}\text { Estrutura do processo de } \\
\text { navegação }\end{array}$ & $\begin{array}{l}\text { constante na amostra } \\
\text { (horiz.) }\end{array}$ & (vertical / horizontal) \\
\hline 10 & $\begin{array}{l}\text { Produtos pré customizados } \\
\text { (livraria) }\end{array}$ & analisado & presença/ausência \\
\hline 11 & Recomendações & analisado & presença/ausência \\
\hline 12 & $\begin{array}{l}\text { Status do processo de } \\
\text { Customização }\end{array}$ & analisado & presença/ausência \\
\hline 13 & Esquema de preço & analisado & presença/ausência \\
\hline 14 & Botão de "Voltar" & analisado & presença/ausência \\
\hline 15 & Botão de "Avançar" & analisado no item 14 & presença/ausência \\
\hline 16 & $\begin{array}{l}\text { Modelo básico para } \\
\text { customização }\end{array}$ & analisado & presença/ausência \\
\hline 17 & $\begin{array}{l}\text { Site diferenciado para a } \\
\text { configuração }\end{array}$ & $\begin{array}{l}\text { constante na amostra } \\
\text { (ausente) }\end{array}$ & presença/ausência \\
\hline 18 & Símbolos diferenciados & $\begin{array}{l}\text { constante na amostra } \\
\text { (ausente) }\end{array}$ & presença/ausência \\
\hline 19 & Status do processo & analisado no item 12 & presença/ausência \\
\hline 20 & $\begin{array}{l}\text { Mapa das alternativas de } \\
\text { customização }\end{array}$ & analisado & presença/ausência \\
\hline 21 & Guia para customização & analisado & presença/ausência \\
\hline 22 & $\begin{array}{l}\text { Estrutura das decisões de } \\
\text { customização no configurador } \\
\text { (passo a passo) }\end{array}$ & analisado & presença/ausência \\
\hline 23 & $\begin{array}{l}\text { Preenchimento automático do } \\
\text { sistema }\end{array}$ & analisado & presença/ausência \\
\hline 24 & Descrição do produto atualizada & analisado no item 27 & presença/ausência \\
\hline
\end{tabular}




\begin{tabular}{|c|c|c|c|c|c|}
\hline 25 & $\begin{array}{l}\text { Quantidade de etapas para } \\
\text { configuração }\end{array}$ & analisado & \multicolumn{3}{|c|}{ quantidade de etapas para a configuração } \\
\hline 26 & $\begin{array}{l}\text { Quantidade de páginas do } \\
\text { processo de configuração }\end{array}$ & analisado no item 25 & \multicolumn{3}{|c|}{ qtd.de páginas para a configuração do produto } \\
\hline 27 & $\begin{array}{l}\text { Resumo do produto } \\
\text { customizado }\end{array}$ & analisado & \multicolumn{3}{|l|}{ presença/ausência } \\
\hline \multicolumn{6}{|c|}{ Constructo-Especificações técnicas } \\
\hline 28 & Conexão SSL & Indisponívelno site & \multicolumn{3}{|l|}{ presença/ausência } \\
\hline 29 & Salvar configuração & analisado & \multicolumn{3}{|l|}{ presença/ausência } \\
\hline 30 & Login & analisado & \multicolumn{3}{|l|}{ presença/ausência } \\
\hline 31 & Scrolling & $\begin{array}{l}\text { constante na amostra } \\
\text { (ausente) }\end{array}$ & \multicolumn{3}{|l|}{ presença/ausência } \\
\hline 32 & Instalação com CD & $\begin{array}{l}\text { constante na amostra } \\
\text { (ausente) }\end{array}$ & \multicolumn{3}{|l|}{ presença/ausência } \\
\hline 33 & Pop-Up & analisado & \multicolumn{3}{|l|}{ presença/ausência } \\
\hline 34 & $\begin{array}{l}\text { Tempo de carregamento } \\
\text { (inferior a 15s) }\end{array}$ & $\begin{array}{l}\text { indisponível no site } \\
\text { (conexão irregular) }\end{array}$ & \multicolumn{3}{|l|}{ inferior/superior } \\
\hline 35 & Plug in & analisado & \multicolumn{3}{|l|}{ presença/ausência } \\
\hline \multicolumn{6}{|c|}{ Constructo - Visualização } \\
\hline 36 & Visualização & analisado & \multicolumn{3}{|l|}{ presença/ausência } \\
\hline 37 & $\begin{array}{l}\text { Imagem final do produto } \\
\text { customizado }\end{array}$ & analisado & \multicolumn{3}{|l|}{ presença/ausência } \\
\hline 38 & Imagem do produto atualizada & analisado no item 36 & \multicolumn{3}{|l|}{ presença/ausência } \\
\hline \multicolumn{3}{|c|}{ 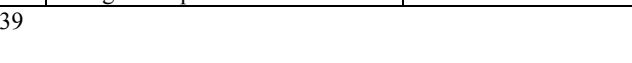 } & Perspectivas finais & analisado & $\begin{array}{l}\text { quantidade de perspectivas } \\
\text { do produto customizado }\end{array}$ \\
\hline \multicolumn{3}{|l|}{40} & $\begin{array}{l}\text { Visualização final rotacionada } \\
\text { (360graus) }\end{array}$ & analisado & presença/ausência \\
\hline \multicolumn{3}{|l|}{41} & $\begin{array}{l}\text { Interatividade com o modelo } \\
\text { final }\end{array}$ & analisado & presença/ausência \\
\hline 42 & & & Animação & analisado & presença/ausência \\
\hline 43 & & & $\begin{array}{l}\text { Etapas de configuração até } \\
\text { aparecer o produto customizado }\end{array}$ & analisado no item 25 & $\begin{array}{l}\text { qtd de passos até a imagem } \\
\text { do produto aparecer }\end{array}$ \\
\hline 44 & & & Dimensão das imagens & indisponível no site & quantidade de pixels \\
\hline 45 & & & $\begin{array}{l}\text { Visualização do produto final } \\
\text { ambientada }\end{array}$ & analisado & presença/ausência \\
\hline Con & ructo - Pedido & & & & \\
\hline 46 & & & Atualização de preço & analisado no item 13 & presença/ausência \\
\hline 47 & & & $\begin{array}{l}\text { Custos dos itens } \\
\text { (customizadores) } \\
\text { individualizados }\end{array}$ & analisado & presença/ausência \\
\hline 48 & & & Botão "Comprar" & analisado & presença/ausência \\
\hline 49 & & & Pedido online & analisado & presença/ausência \\
\hline 50 & & & Forma de pagamento & analisado & presença/ausência \\
\hline 51 & & & Carrinho de compra & $\begin{array}{l}\text { constante na amostra } \\
\text { (ausente) }\end{array}$ & presença/ausência \\
\hline 52 & & & $\begin{array}{l}\text { Informações necessárias para } \\
\text { registro (login) }\end{array}$ & analisado no item 30 & descritivo \\
\hline 53 & & & $\begin{array}{l}\text { Informação da previsão de } \\
\text { entrega do produto }\end{array}$ & analisado & presença/ausência \\
\hline 54 & & & Prazo de entrega do produto & analisado & $\begin{array}{l}\text { quantidade de dias para a } \\
\text { entrega }\end{array}$ \\
\hline 55 & & & Forma de transporte & $\begin{array}{l}\text { constante na amostra } \\
\text { (ausente) }\end{array}$ & descritivo \\
\hline Con & ructo - Extras & & & & \\
\hline 56 & & & Deficiências do configurador & não analisado & descritivo \\
\hline 57 & & & Fórum de discussão & analisado & presença/ausência \\
\hline 58 & & & Comunidades & analisado no item 57 & presença/ausência \\
\hline 59 & & & Produto exótico & não analisado & $\operatorname{sim} /$ não \\
\hline 60 & & & $\begin{array}{l}\text { O configurador está cadastrado } \\
\text { na base de dados }\end{array}$ & não analisado & $\operatorname{sim} /$ não \\
\hline 61 & & & Nome da empresa & $\begin{array}{l}\text { nãoanalisado } \\
\text { (registrado) }\end{array}$ & nome da companhia \\
\hline 62 & & & Web site do configurador & $\begin{array}{l}\text { nãoanalisado } \\
\text { (registrado) }\end{array}$ & endereço de www \\
\hline 63 & & & Setor industrial & nãoanalisado & Setor industrial \\
\hline 64 & & & $\begin{array}{l}\text { Descrição das possibilidades do } \\
\text { configurador }\end{array}$ & analisado no item 11 & presença/ausência \\
\hline 65 & & & Produto ou serviço & nãoanalisado & produto/serviço \\
\hline 66 & & & Sistema produtivo & não analisado & descritivo \\
\hline 67 & & & Promoção ou venda & analisado no item 48 & promoção/venda \\
\hline 68 & & & $\mathrm{~B} 2 \mathrm{C} / \mathrm{B} 2 \mathrm{~B}$ & $\begin{array}{l}\text { não analisado } \\
\text { (registrado) }\end{array}$ & $\mathrm{B} 2 \mathrm{~B} / \mathrm{B} 2 \mathrm{C}$ \\
\hline 69 & & & $\begin{array}{l}\text { Nome da empresa } \\
\text { desenvolvedora do configurador }\end{array}$ & não analisado & $\begin{array}{l}\text { nome da empresa } \\
\text { desenvolvedora }\end{array}$ \\
\hline 70 & & & Idioma & $\begin{array}{l}\text { não analisado } \\
\text { (registrado) }\end{array}$ & idioma \\
\hline 71 & & & Contato da empresa & não analisado & nome e cargo \\
\hline Rec & sos presentes na amostra e inc & dos para análise & & & \\
\hline 72 & & & Simulação de financiamento & incluído na análise & presença/ausência \\
\hline 73 & & & $\begin{array}{l}\text { Encaminhamento para um } \\
\text { vendedor físico próximo }\end{array}$ & incluído na análise & presença/ausência \\
\hline 74 & & & $\begin{array}{l}\text { Encaminhamento da proposta } \\
\text { online para avaliação }\end{array}$ & incluído na análise & presença/ausência \\
\hline
\end{tabular}




\begin{tabular}{|l|l|l|l|}
\hline 75 & $\begin{array}{l}\text { Informação de estoque de } \\
\text { veículos }\end{array}$ & incluído na análise & presença/ausência \\
\hline 76 & $\begin{array}{l}\text { Acesso ao configurador está } \\
\text { presente na metanavegação }\end{array}$ & incluído na análise & presença/ausência \\
\hline
\end{tabular}

\begin{tabular}{|c|c|c|c|}
\hline \multirow{2}{*}{\multicolumn{2}{|c|}{ Recurso }} & \multicolumn{2}{|c|}{ Presença no Config. } \\
\hline & & \multirow{2}{*}{$\begin{array}{l}\text { Básico } \\
6^{13 \%}\end{array}$} & \multirow{2}{*}{$\begin{array}{l}\text { Avançado } \\
13^{22 \%}\end{array}$} \\
\hline 1 & Botão de ajuda no configurador & & \\
\hline 2 & Política de privacidade & $44^{95 \%}$ & $59^{100 \%}$ \\
\hline 3 & Distância desde a página inicial até iniciar o configurador & $\bar{X}=3,48^{* *}$ & $\bar{X}=2,42 * *$ \\
\hline 4 & $\mathrm{O}$ acesso ao configurador está presente na metanavegação & $9^{20 \% * *}$ & $55^{93 \%^{* *}}$ \\
\hline 5 & Menu de perguntasfrequentes & $9^{35 \% *}$ & $16^{15 \% *}$ \\
\hline 6 & Contatoparainformaçõesadicionais & $43^{93 \%}$ & $58^{98 \%}$ \\
\hline 7 & Demonstrativo do processo de customização & $44^{96 \%}$ & $59^{100 \%}$ \\
\hline 8 & Produtosprécustomizados (livraria) & $45^{98 \%}$ & $59^{100 \%}$ \\
\hline 9 & Recomendações & $5^{11 \%^{* *}}$ & $24^{41 \%^{* *}}$ \\
\hline 10 & Esquema de preço & $34^{74 \% * *}$ & $57^{97 \%^{* *}}$ \\
\hline 11 & Botão de "Voltar" & $43^{93 \%}$ & $588^{98 \%}$ \\
\hline 12 & Modelobásicoparacustomização & $46^{100 \%}$ & $59^{100 \%}$ \\
\hline 13 & Status do processo de Customização & $43^{93 \%^{*}}$ & $59^{100 \% *}$ \\
\hline 14 & Mapa das alternativas de customização & $42^{91 \%^{*}}$ & $59^{100 \% *}$ \\
\hline 15 & Guiaparacustomização & $2^{4 \%}$ & $6^{10 \%}$ \\
\hline 16 & Estrutura das decisões de customização no configurador (passo a passo) & $46^{100 \%}$ & $59^{100 \%}$ \\
\hline 17 & Preenchimentoautomático do sistema & $24^{52 \%}$ & $39^{66 \%}$ \\
\hline 18 & Quantidade de etapas para configuração & $\bar{X}=4,83^{* *}$ & $\bar{X}=5,97 * *$ \\
\hline 19 & Resumo do produtocustomizado & $34^{74 \% * *}$ & $57^{97 \% * *}$ \\
\hline 20 & Salvarconfiguração & $10^{22 \%^{*}}$ & $24^{41 \% *}$ \\
\hline 21 & Login & $2^{4 \% \%^{*}}$ & $11^{19 \%^{*}}$ \\
\hline 22 & Pop up & $0^{0 \% *}$ & $10^{17 \%^{*}}$ \\
\hline 23 & Plug in & $0 \%$ & $11^{2 \%}$ \\
\hline 24 & Visualização & $40^{87 \%}$ & $55^{93 \%}$ \\
\hline 25 & Imagem final do produto customizado & $33^{72 \%^{*}}$ & $55^{93 \% *}$ \\
\hline 26 & Perspectivasfinais & $\bar{X}=1,63^{* *}$ & $\bar{X}=3,19 * *$ \\
\hline 27 & Visualização final rotacionada (360graus) & $3^{7 \% \%^{*}}$ & $12^{20 \%^{*}}$ \\
\hline 28 & Interatividade com o modelo final & $1^{2 \%}$ & $7^{12 \%}$ \\
\hline 29 & Animação & $0 \%$ & $1^{2 \%}$ \\
\hline 30 & Visualização do produto final ambientada & $1^{2 \%}$ & $4^{12 \%}$ \\
\hline 31 & Custos dos itens (customizadores) individualizados & $27^{59 \%^{* *}}$ & $54^{92 \% \text { *** }}$ \\
\hline 32 & Botãocomprar & $0 \%$ & $1^{2 \%}$ \\
\hline 33 & Pedidoonline & $00 \%$ & $0 \%$ \\
\hline 34 & Forma de pagamento & $1^{2 \%}$ & $0 \%$ \\
\hline 35 & O sistema informa a previsão de entrega do produto & $0 \%$ & $0 \%$ \\
\hline 36 & Prazo de entrega do produto & $00 \%$ & $00^{0 \%}$ \\
\hline 37 & Simulação de financiamento & $15^{33 \%}$ & $30^{51 \%}$ \\
\hline 38 & Encaminhamento para um vendedor físico próximo & $32^{70 \%}$ & $44^{70 \%}$ \\
\hline 39 & Encaminhamento da proposta online para avaliação & $15^{30 \%}$ & $288^{50 \%}$ \\
\hline 40 & Informação de estoque de veículos & $49 \%$ & $8^{14 \%}$ \\
\hline 41 & Fórum de discussão & $6^{13 \%}$ & $3^{13 \%}$ \\
\hline
\end{tabular}

